\title{
A method to maximise forest profitability through optimal rotation period selection under various economic, site and silvicultural conditions
}

\author{
Tohru Nakajima ${ }^{1 *}$, Norihiko Shiraishi ${ }^{1}$, Hidesato Kanomata ${ }^{2}$ and Mitsuo Matsumoto ${ }^{3}$
}

\begin{abstract}
Background: Maximising forest profitability is important from both economic and ecological perspectives. Managers of forest areas gain utility by optimising profits, and maximising the efficiency of a forest stand is also beneficial to the natural environment. This study presents a method to estimate and visualise forestry profitability based on variables defined in previous studies. The design space included economic and forest stand factors that can affect profitability. A contribution index analysis identified factors that significantly impact profitability, and these factors were then applied to data collected from a forest area in Japan. The effects of the two primary factors, discount rate and rotation period length, on a measure of profitability, the soil expectation value, were visualised in three-dimensional space.
\end{abstract}

Methods: The site used in this study, located by Morotsuka village in the Miyazaki Prefecture, Japan. Variables previously found to have significant effects on forestry profitability were used to define a design space of variables for calculating and displaying profitability, after which data from the cited study were used to estimate the variables' SEV contribution indices. The effects of the important factors for forestry profitability were then analysed and visualised. Dimensions of the design space were constructed from previously published forestry inventory data and consisted of two stand condition factors, three site condition factors, one economic condition factor and one silvicultural planning factor. This study used previously published inventory data regarding stand age, site index and tree species. Additionally, the forestry profit simulator was used to estimate the optimal rotation period in terms of soil expectation value. The relationships between SEV and these significant factors were then graphically visualised. The significant factors identified as described above were used to estimate SEV-based profitability distributions, based on the inventory data used to construct the design space and optimal rotation periods, for the studied forest.

Results: Changes in rotation period affected forestry profitability. However, the effect depended on stand, site and economic conditions. In scenarios characterised by relatively low site productivity index and harvesting area, which results in low profitability, rotation period changes did not have a strong effect on profitability. On the other hand, it was vital to select the optimal rotation period for high profitability areas as even a small deviation had a significant impact on profitability. Furthermore, it was shown that by synchronising the harvesting times of small, adjacent stands, the overall profitability increased through reductions in forest management costs.

(Continued on next page)

\footnotetext{
* Correspondence: nakajima@fr.a.u-tokyo.ac.jp

1 Laboratory of Forest Management, Graduate School of Agricultural and Life Sciences, University of Tokyo, 1-1-1 Yayoi, Bunkyo-ku, Tokyo 113-8657, Japan Full list of author information is available at the end of the article
} 
(Continued from previous page)

Conclusions: These results can help local forest management increase profitability through cooperation with individual forest owners. The presented method also has risk management applications, as it could be used to estimate the effects of external uncertainty variables on forest profitability.

Keywords: Forest profitability, Soil expectation value, Silvicultural practices, Stand conditions, Site conditions, Rotation period

\section{Background}

There is a very long tradition of humans managing forests to obtain timber and various other products for both personal use and sale (Westoby 1989). Currently, there is a global consensus that sustainable forest management should be assured for the present and future. It is important that forest management is sustainable from both economic and environmental perspectives. Historically, uncontrolled logging has had detrimental effects on valued characteristics of forest environments, such as biodiversity, carbon stocks, aesthetic appeal and amenity value (Pukkala 2002). However, timber production does not necessarily affect all of these characteristics negatively. Instead, the relationships between timber production and some valued environmental characteristics can be synergetic rather than divisive (Cademus et al. 2014), and this synergy can exist between two or more forest products and services, such as biodiversity (Probst and Crow 1991), bioenergy-carbon sinks (Hoel and Sletten 2016) and multiple-use management (Hornbeck and Swank 1992). Moreover, Lu et al. (2014) provided evidence for a synergistic relationship between soil organic carbon and soil total nitrogen during timber production. On the other hand, provisioning services, which include wild-food production and timber harvesting, often cause large tradeoffs with ecosystem functions such as water quality, flood control and ecotourism potential (Marianov et al. 2004; Millennium Ecosystem Assessment Board 2005). For example, the reduction of $\mathrm{CO}_{2}$ emissions could be facilitated by both maintaining forests' carbon stocks and sustainably producing timber as a carbon-neutral material (IPCC 2000; IPCC 2007). It has also been shown that appropriate forest management, when compared to the practice of abandoning an area after planting, can result in more varied forest types with greater biodiversity and amenity value (Boyce 1995).

Certain management practices help to maintain both economic and environmental sustainability in planted forests used for timber production. The rotation period is especially important in silvicultural management, as it determines logging intervals, and can dramatically affect stand conditions (Bettinger et al. 2009). For example, changes in the rotation period can alter the age distribution in a stand, potentially skewing it towards a population of younger trees. Previous studies have defined rotation periods in various terms, such as physical, technical and financial parameters, depending on the forest management objective (Bettinger et al. 2009; Hiley 1967). Numerous studies have also shown that the physical rotation age, which is based on the life span of a tree, varies greatly between species. For example, Sequoia sempervirens (D.Don) Endl. and Alnus rubra Bong. have physical rotation values of over 1000 and less than 100 years, respectively (Harrington 1990; Olson et al. 1990). Another definition, the technical rotation age, is based on the size of tree a particular economic market requires.

The Faustmann formula proposes that a rotation period that maximises the soil expectation value (SEV) will result in a final cutting age that is economically sustainable (Faustmann 1968). The Pressler formula (1860) can also be used to calculate the optimal rotation period. However, Samuelson (1976) suggested, following a discussion about the validities of the Faustmann and Pressler formula, that the Faustmann formula has better validity than other optimal rotation period formulae. The initial formula for maximising SEV has been modified to include variables that represent environmental characteristics (Hartman 1976). Hyytiäinen et al. (2004) included the optimal rotation simulation formula into their process-based forest growth model. Formulae for the optimal rotation period were originally applied only to even-aged forests but have recently been used to calculate optimal rotation periods for uneven-aged and natural forests (Chang and Gadow 2010). Previous studies have also investigated how economic conditions affect forest profitability; for example, Parajuli and Chang (2012) included timber price in their sensitivity analyses. On the other hand, Halbritter and Deegen (2015) investigated the relationship between silvicultural practices and rotation period by analysing how planting density influences the optimal rotation period. Ultimately, the optimal rotation period is site-specific, and the SEV depends on economic, stand and site conditions, as well as silvicultural practices used. A previous study showed that a few subjective conditions can change the SEV and optimal rotation period when forest management regimes aiming to maximise the SEV are applied (Davis et al. 2001).

However, there have been few (if any) attempts to determine and visualise forest profitability as a solution 
space optimised by calculating SEV from characteristics of the local forest environment.

Although previous studies have analysed how discount rate affects SEV (Davis et al. 2001), there have been few attempts to identify long-term forest management strategies through a multifactorial analysis. There is a need for a comprehensive analysis in Japan since the government has proposed that the target for annual timber production should increase from 23 million $\mathrm{m}^{3}$ to approximately 50 million $\mathrm{m}^{3}$ in the future. This is an achievable target as the average annual growth of Japan's forest resources is estimated to be 80 million $\mathrm{m}^{3}$ (Forestry Agency 2014). Thus, it is important to analyse the various factors that affect stand profitability so that timber production can be increased without jeopardising the sustainable management of forest resources. The objective of the presented study was to simulate how stand, site and economic conditions, as well as final cutting silvicultural practices, affect SEV distribution in a Japanese forestry area characterised by high productivity, such as the Miyazaki prefecture.

The present study used a contribution analysis to determine how stand, site and economic conditions, along with silvicultural planning, affect forest profitability. The resulting variables were then used to generate a solution space displaying SEV maxima and optimal rotation periods on both forest and stand levels. Furthermore, the distribution of SEV based on rotation periods was estimated in an actual forest area. In addition to describing the methodology and presenting the results, we also provide forest management recommendations that aim to maintain economic sustainability.

\section{Methods}

\section{Study site}

The site used in this study, located by Morotsuka village in the Miyazaki Prefecture, Japan, has been studied in previous research that includes a detailed forest inventory (Nakajima et al. 2011a).

The timber productivity of this site is amongst the highest in Japan (Miyazaki Prefecture Government
2015). It has a warm temperate climate, with a mean annual temperature of $14{ }^{\circ} \mathrm{C}$ and mean annual rainfall of $2445 \mathrm{~mm}$. Forests cover about 17,785 ha in the area and planted forests about 12,541 ha (71\% of the total). The study areas hosted Cryptomeria japonica (Thunb. ex L.f.) D.Don private forests with a bell-shaped tree age distribution, which is typical for Japanese planted forests of this species (Forestry Agency 2007). The C. japonica stands in the target area were mostly between 30 and 50 years old. The most frequent stand age was approximately 30 years.

In 2004, the study site was certificated by the Forest Stewardship Council (FSC). Therefore, it must not only be economically sustainable but also maintain environmental functions defined by an independent organisation (Gulbrandsen 2005).

\section{Data analysis}

Variables previously found to have significant effects on forestry profitability (Nakajima et al. 2011a) were used to define a design space of variables for calculating and displaying profitability (expressed as SEV), after which data from the cited study were used to estimate the variables' SEV contribution indices. The effects of the important factors for forestry profitability were then analysed and visualised as described below.

\section{Design space modelling}

Dimensions of the design space were constructed from previously published forestry inventory data (Nakajima et al. 2011a) and consisted of two stand condition factors (site index class and stand age), three site condition factors (area, and distances from forest road and strip road; referred to as ground condition variables in the previous study), one economic condition factor (discount rate) and one silvicultural planning factor (rotation period) as shown in Table 1. In this study, discount rate reflects the interest rate that is used to estimate the present value of future cash flows (Eatwell et al. 1987; Winton 1951). Discount rate is a measure of the capital cost and expected yield of investments.

Table 1 The design space of factors affecting forestry profitability

\begin{tabular}{|c|c|c|c|c|c|}
\hline Category & Item & Unit & Maximum & Intermediate & Minimum \\
\hline \multirow[t]{2}{*}{ Stand condition } & Stand age & Year & 100 & 30 & 1 \\
\hline & Site index class & & 1 & 2 & 3 \\
\hline \multirow[t]{3}{*}{ Ground condition } & Distance from strip road & $\mathrm{m}$ & 1500 & 500 & 0 \\
\hline & Distance from forest road & $\mathrm{m}$ & 1500 & 500 & 0 \\
\hline & Area & ha & 15 & 0.5 & 0.01 \\
\hline Economic condition & Discount rate & $\%$ & 7 & 3 & 1 \\
\hline Silvicultural planning & Rotation period & Year & 100 & 65 & 30 \\
\hline
\end{tabular}

The intermediate values represent the mean values, with the exception of "stand age." For this item, the intermediate value represents a modal value, as the most common stand age within the study site was approximately 30 years 
Minimum and maximum values were set for all factors, and then, a contribution index analysis was performed to determine each factor's effect on forest profitability, by calculating profitability (SEV) at values spanning from their minima to maxima.

\section{Contribution analysis of selected factors}

This study used previously published inventory data (Nakajima et al. 2011a) regarding stand age, site index and tree species. Additionally, the forestry profit simulator described by Nakajima et al. (2011a) was used to estimate the optimal rotation period in terms of soil expectation value. The model used the inventory data to simulate how factors such as rotation period length, site index and discount rate affect SEV.

The stem volume, timber volume and number of stems and timber logs were estimated from the local yield table with either the Construction System or the Woodmax algorithm (Nakajima et al. 2011a). The felling, logging, bunching and skidding productivity $\left(\mathrm{m}^{3}\right.$ person $^{-1}$ day $^{-1}$ ) were then calculated by applying formulas described in Table 1 to the variables that had been estimated from historical harvesting records.

The average stem and timber volumes were calculated by dividing the total stem and timber volume by the number of stems and timber logs, respectively, which had been derived from the local yield table through either the construction system or the WoodMax algorithm. The distance from forest roads was obtained from forest inventory data published by the Morotsuka village government. Other variables are shown in Additional file 1: Table S1 along with the silvicultural costs, which were proposed by the forest association during interviews and based on historical records of silvicultural practices. The interviews were conducted during the 2009 winter season. Staff members from the Mimi River Forest Association and a forest owner in the study site were invited to oral interviews regarding the practical harvesting area, silvicultural costs and subsidies. The same interview pool was used in a previous study (Nakajima et al. 2011a). The response rate of these questionnaire surveys was close to $100 \%$.

Forest inventory data such as stand age, tree species and site index can be used as input data for the stand growth model presented in a previous study (Nakajima et al. 2011a).

A subsidy was not directly applied as a variable in this study. A subsidy was applied as a constant as mentioned below.

The Japanese government subsidises various silvicultural practices in planted forests irrespective of the tree species, providing approximately $70 \%$ of the planting, thinning and other silvicultural costs. For this reason, these subsidies were not included as a variable in this study but rather treated as a constant with a value of $70 \%$ of silvicultural costs (Additional file 1: Table S1(b)). The reality of these subsidy systems was confirmed by checking active silvicultural areas throughout Japan and comparing the subsidies they received with the implemented silvicultural practices (Hiroshima and Nakajima 2006).

First, forestry profitability was estimated as SEV using the following two equations (Davis and Johanson 1987; Davis et al. 2001).

$$
S E V_{1}=\frac{a}{(1+i)^{w}-1}
$$

where $\mathrm{SEV}_{1}$ is the present value of the land with a stand currently at age $1, a$ is the net income received at rotation age ( $w$ in years) every $w$ years starting at the end of year $w$ and $i$ is the discount rate (in decimals). However, the most frequent stand age in our study is approximately 30 years. Thus, the stands reflect relatively young forest, and $w 1$ would be almost equal to $w$. If the optimal rotation period $(w)$ derived from maximising $\mathrm{SEV}_{1}$ is lower than the current stand age $(t)$, it is impossible to carry out the optimal rotation period as the first final cutting age. Strictly speaking, the first optimal rotation period should not be lower than the current stand age. Therefore, we defined the first rotation period $(w 1)$ derived from maximising $\mathrm{NR}_{w 1}$, after which the subsequent rotation periods $(w)$ were calculated separately. Therefore, the first optimal rotation periods were selected as rotation periods in this study.

$$
S E V_{t}=\frac{N R_{w 1}+S E V_{1}}{(1+i)^{w 1-t}}
$$

where $\mathrm{SEV}_{t}$ is the present value of a stand currently at age $t, \mathrm{NR} w_{1}$ is the net return of the stand at age $w 1$ and $w 1-t$ is the number of years before the stand reaches rotation harvest age.

The variables regarding forestry profitability ( $a$ and $\mathrm{NR} w_{1}$ ) in Eqs. (1) and (2) were based on results from a previous study (Nakajima et al. 2011a). The discount rate and rotation age $\left(i\right.$ and $w_{1}$ ) followed the ranges shown in Table 1. The ranges of initial conditions were defined as the maxima and minima for the factors shown in Table 1.

A contribution index, which treated forestry profitability as an objective function and was based solely on main effects (Gu 2002), was also calculated:

$$
C_{i}=\frac{V_{i}}{V\left[S E V_{t}\right]}
$$

Here, $C_{i}$ is the contribution index of the stand age, site index class, distance from strip road, distance from forest road, stand area, discount rate and rotation period, when $i=1$ to 7 , respectively; $V\left[S E V_{t}\right]$ is the variance of forestry profits over the total area; and $V_{i}$ is the variance of SEV depending on the listed factors $(i=1-7)$. 
To determine the effect of each factor $(i=1, \ldots, 7)$ on forest profitability, their contributions to its variance were calculated. The relationship between $V\left[\mathrm{SEV}_{t}\right]$ and $V_{i}$ was calculated using the following formula, in conjunction with the smoothing spline ANOVA method (Gu 2002).

$$
\begin{aligned}
& V\left[S E V_{t}\right]=\sum_{i=1}^{7} V_{i} \\
& V_{i}=\frac{1}{n} \sum_{j=1}^{n}\left(S E V_{i, j}-\overline{S E V_{i}}\right)^{2}
\end{aligned}
$$

where $S E V_{i, j}$ is the SEV of factor $i$ depending on the variable $j$, which represents sample id.

\section{Visualisation of stand-level relationships between SEV and significant factors}

Only factors with a calculated contribution to SEV of at least $0.1 \%$ were included in the study. All others were excluded, and the identification of significant factors ceased when the cumulative contribution of the included factors exceeded 99.7\%. The relationships between SEV and these significant factors were then graphically visualised.

In addition to the ANOVAs mentioned above, a multiple regression analysis (Leona et al. 1996) was performed to estimate how stand, site and economic conditions, as well as silvicultural planning, influence forest profitability, measured as SEV. Only these factors were included in the multiple regression analysis because they met the requirements set for the contribution index analysis.

Using these factors, the SEV was calculated as

$$
\begin{aligned}
& \mathrm{SEV}=a_{0}+a_{1} x_{1}+a_{2} x_{2}+a_{3} x_{3}+a_{4} x_{4} \\
& \mathrm{SEV}=a_{0}+a_{1} x_{1}+a_{2} x_{2}+a_{3} x_{3}+a_{4} x_{4} \ldots a_{n} x_{n}
\end{aligned}
$$

where $x_{1}, x_{2}, x_{3}, x_{4} \ldots x_{n}$ represent selected variables derived from the analysis mentioned above and $a_{0}, a_{1}$, $a_{2}, a_{3}, a_{4} \ldots a_{n}$ are constants. We used stepwise selection to determine the variables that would be included in the final model with a requirement that all included variables have a partial $F$ statistic with a probability less than, or equal to, 0.05. Statistical analyses were performed in the software package Excel Statistics 2006 (Microsoft, Redmond, WA) according to recommendations from Social Survey Research Information (Social Survey Research Information 2006).

\section{Estimation of forest-level profitability distributions}

The significant factors identified as described above were used to estimate SEV-based profitability distributions, based on the inventory data used to construct the design space and optimal rotation periods, for the studied forest.

To confirm the robustness of detected effects of increasing the harvesting area on forestry profitability, we calculated two SEV distributions depending on localscale rotation periods. The local-scale rotation periods are used as a generic term for the optimised rotation periods of the studied forest area. The total stand area was approximately 1700 ha, which was selected randomly based on a previous study (Nakajima et al. 2011a).

In both cases, we excluded stands with a negative SEV (yen ha ${ }^{-1}$ ); the management of these stands would be unprofitable, causing forest owners to abandon them. The first SEV distribution is based on the assumption that the harvesting area is equal to the target stand area. This distribution is equal to the SEV estimated through Eq. 2. In the calculation of the second distribution, it was assumed that stands with areas less than 1 ha would be treated as if their harvesting area was 1 ha. However,

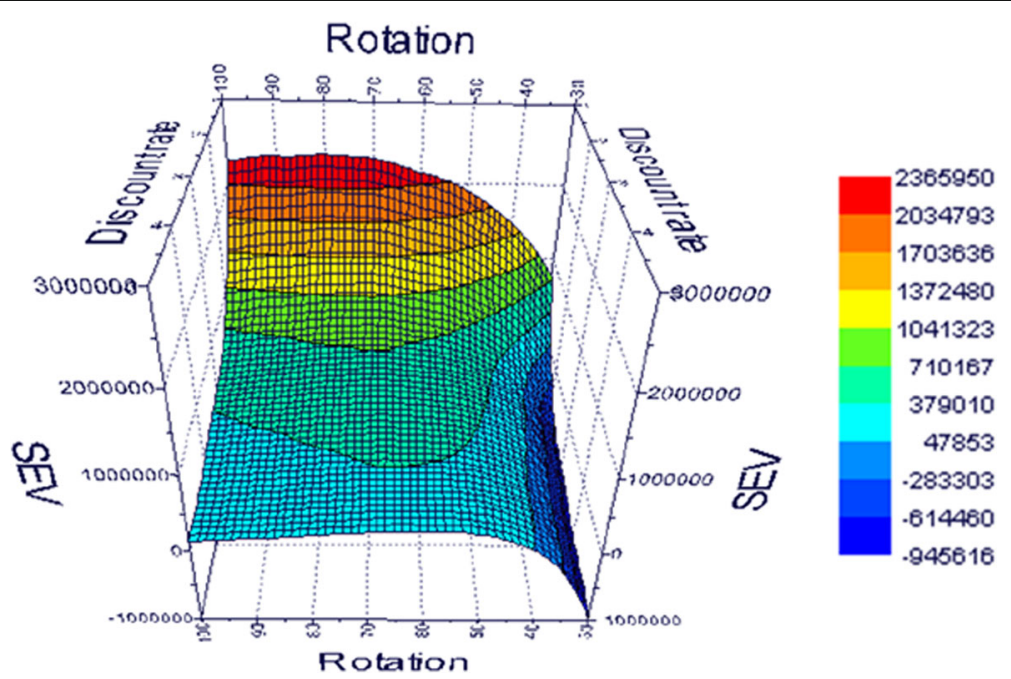

Fig. 1 The three-dimensional SEV (yen) solution space defined by discount rate (\%) and rotation period (year), with site index class, stand age and harvesting area set to 1, 30 years and 1 ha, respectively 
the SEV value can change under certain conditions, for example, if the timber price dramatically increases. In this situation (a higher timber price), stands that initially had a negative SEV may actually have a positive SEV. In this way, it may not be rational for forest owners to exclude stands with negative SEV values because timber prices fluctuate, and future SEV values could be positive. However, it is difficult to predict the future timber price. Additionally, the timber price has not dramatically changed during recent years. Under these conditions, excluding a negative SEV may be rational for forest owners. Therefore, this study fixed the timber price based on results from a previous study (Nakajima et al. 2011a).

\section{Results}

\section{Key factors affecting profitability}

The contribution indices of discount rate, rotation period, site index class, harvesting area and stand age to forest profitability were $0.71,0.16,0.7,0.05$ and 0.02 , respectively. Distances from forest and strip roads did not meet the criteria for significant factors and thus were not included in the analysis. The stand age was set to 30 years for the contribution index analysis as this was the most frequent stand age within the study site.

The three-dimensional visualisation presented in Fig. 1 illustrates how changes in discount rate and rotation period affect profitability when site index class, stand age and harvesting area were set to 1, 30 years and 1 ha, respectively. The figure shows the maximum SEV plotted against the discount rate and rotation period, as according to the contribution index analysis, these two factors had the largest impact on profitability. The optimal rotation period ranges from 65 years (discount rate $5 \%)$ to 80 years (discount rate $1 \%$ ).

Differences in current stand condition and other factors could alter the shape of the solution space, but the effects of discount rate and rotation period on forest profitability would remain similar.

The results show not only that SEV decreases as the discount rate increases but also that the rotation period affects SEV. The three-dimensional solution space reveals a point where a specific rotation period and discount rate maximise SEV. To determine the optimal rotation period, the discount rate can be held at a constant level and the solution space can be transformed into a digital elevation model (DEM). From this, the rotation period curve can be treated as a "mountain edge" and measured with the flow accumulation algorithm in ArcGIS 10 (ESRI, Redlands, CA).

The multiple regression analysis produced the following profitability model for planted forests in Japan:

$$
\begin{aligned}
\mathrm{SEV}= & 2044500+656380 A-417510 D \\
& +6981.8 R-793220 S I
\end{aligned}
$$

where $A$ is the area (ha), $D$ is the discount rate (\%), $R$ is the rotation period (year) and $S I$ is the site index class.

The fit of the model was significant, and the $p$ values for area (ha), discount rate (\%), rotation (year) and site index class were all less than 0.01 . The constants representing area and rotation period are positive, which means that SEV increases when the rotation period and/ or the harvested area increase. On the other hand, the constants representing discount rate and site index class are negative, which means that SEV decreases when the discount rate and/or the site index class increase. This multiple regression analysis identifies the significant factors that affect profitability and presents a statistic model that can simplify the calculation of forest profitability at other planted forests in Japan.

Contour maps in digital elevation models illustrate the relationship between optimal rotation period and discount rate in various scenarios.

This method for determining the optimal rotation period was then applied to scenarios with the minimum harvesting area set to $1,1.5$ or 3 ha and site index class set to 1,2 or 3 . In the nine resulting possibilities, the optimal rotation period was charted via the mountain edge method over the solution space, as shown in Fig. 2. It was noted that an increase in harvesting area leads to an increase in the SEV and a decrease in the optimal rotation period.

The SEV ranges from approximately -9.45 million to 46.11 million, -17.40 million to 29.40 million and -26.30 million to 20.70 million yen $\mathrm{ha}^{-1}$ for site indices of 1, 2 and 3, respectively (Fig. 2). Hence, the range of SEV widens as the site index and harvesting area increase. Furthermore, the SEV range shifts when the discount rate changes. For example, the SEV ranges for site index classes 1, 2 and 3 are approximately 1.04 million to 4.61 million, 0.26 million to 1.64 million and 0.14 million to 1.28 million yen $\mathrm{ha}^{-1}$, respectively, when the discount rate is between 1 and $2 \%$, but approximately 47,853 million to 2.37 million, $-23,000$ million to 1.24 million and -1.63 million to 1.01 million yen $\mathrm{ha}^{-1}$, respectively, when the discount rate is between 2 and $5 \%$.

\section{Effects of optimal rotation period on SEV distributions}

The dependence of SEV on optimal rotation periods (under the two assumptions mentioned above) is illustrated in Fig. 3.

The total SEV of the distributions under the first assumption (that stands with negative SEV would be excluded) at discount rates of 1,3 and $5 \%$ are approximately $2.14,6.46$ and 3.92 trillion yen, respectively, $50 \%$ of which falls within the age ranges of 30-44, 30-44 and 30-64 


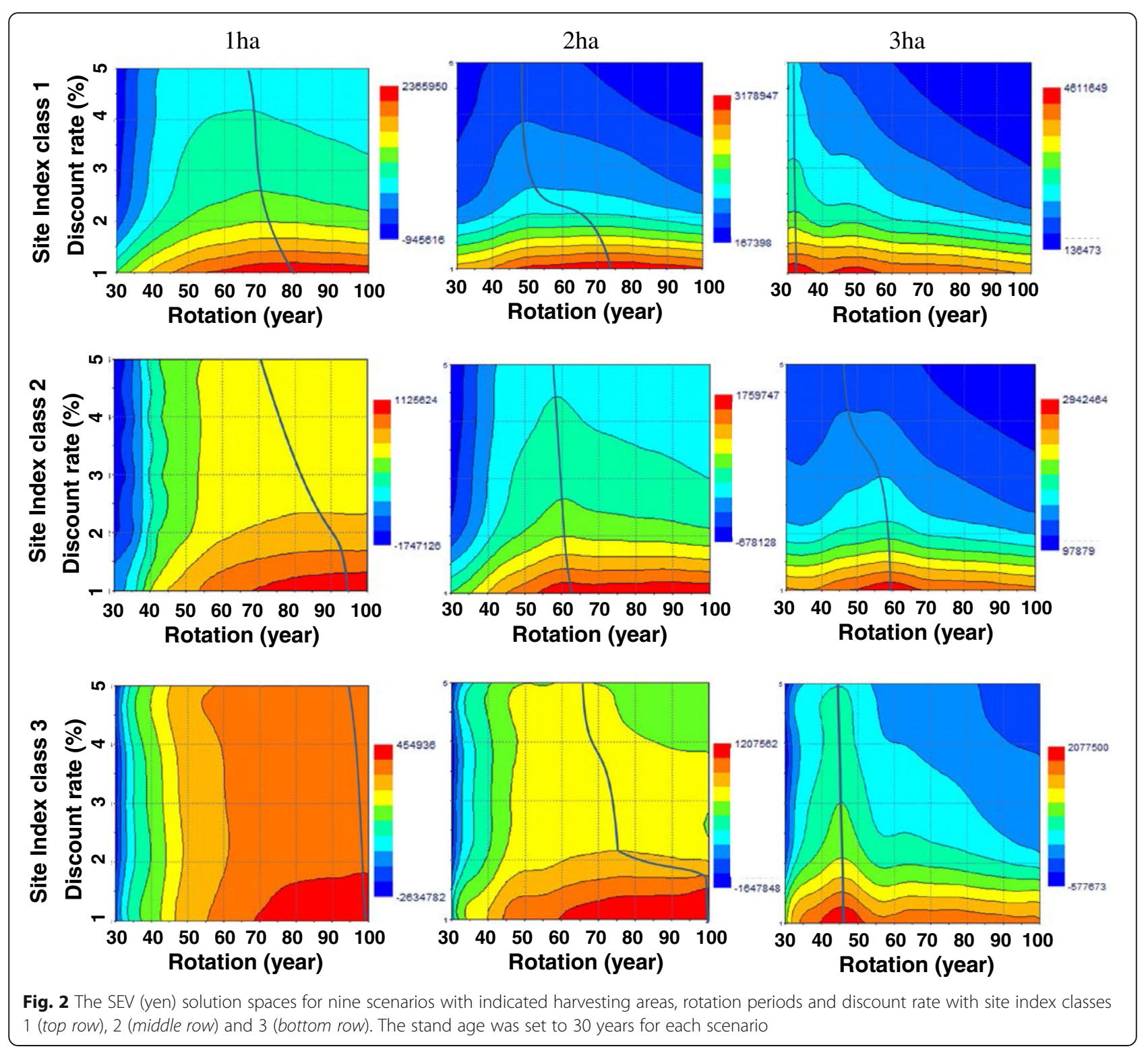

years, respectively (Fig. 3a-c). Profitability was generally highest with relatively short rotation periods. The total annually harvested areas, under the first assumption, at discount rates of 1, 3 and 5\% were approximately 952, 731 and 722 ha, respectively (Fig. $3 \mathrm{a}-\mathrm{c}$ ). The average rotation periods under these discount rates were 70, 59 and 54 years, respectively.

In the SEV distributions obtained with the second assumption, the annually harvested areas at discount rates of 1,3 and $5 \%$ were 1774, 1733 and 1025 ha, respectively (Fig. $3 \mathrm{~d}-\mathrm{f}$ ). The average rotation periods in these cases, at the same discount rates, were 80, 70 and 60 years, respectively. These distributions were based on the assumption that stands with areas $\leq 1$ ha would be treated as 1-ha stands during harvesting. This was due to the results of a questionnaire survey, which demonstrated that the minimal viable harvesting area was 1 ha. As the average stand area was approximately 0.5 ha, this assumption was intended to determine how profitability would increase if multiple adjacent small stands were harvested simultaneously in order to lower costs. For example, two 0.5-ha stands could be harvested at the same time, effectively creating a harvesting area of 1 ha. This simulation showed that simultaneous harvesting of small plots could raise profitability by 186, 242 and $138 \%$ at discount rates of 1,3 and $5 \%$, respectively.

\section{Discussion}

It was important to select only factors for the study that had significant effects on forest profitability, defined as having an effect of at least $0.1 \%$. The 


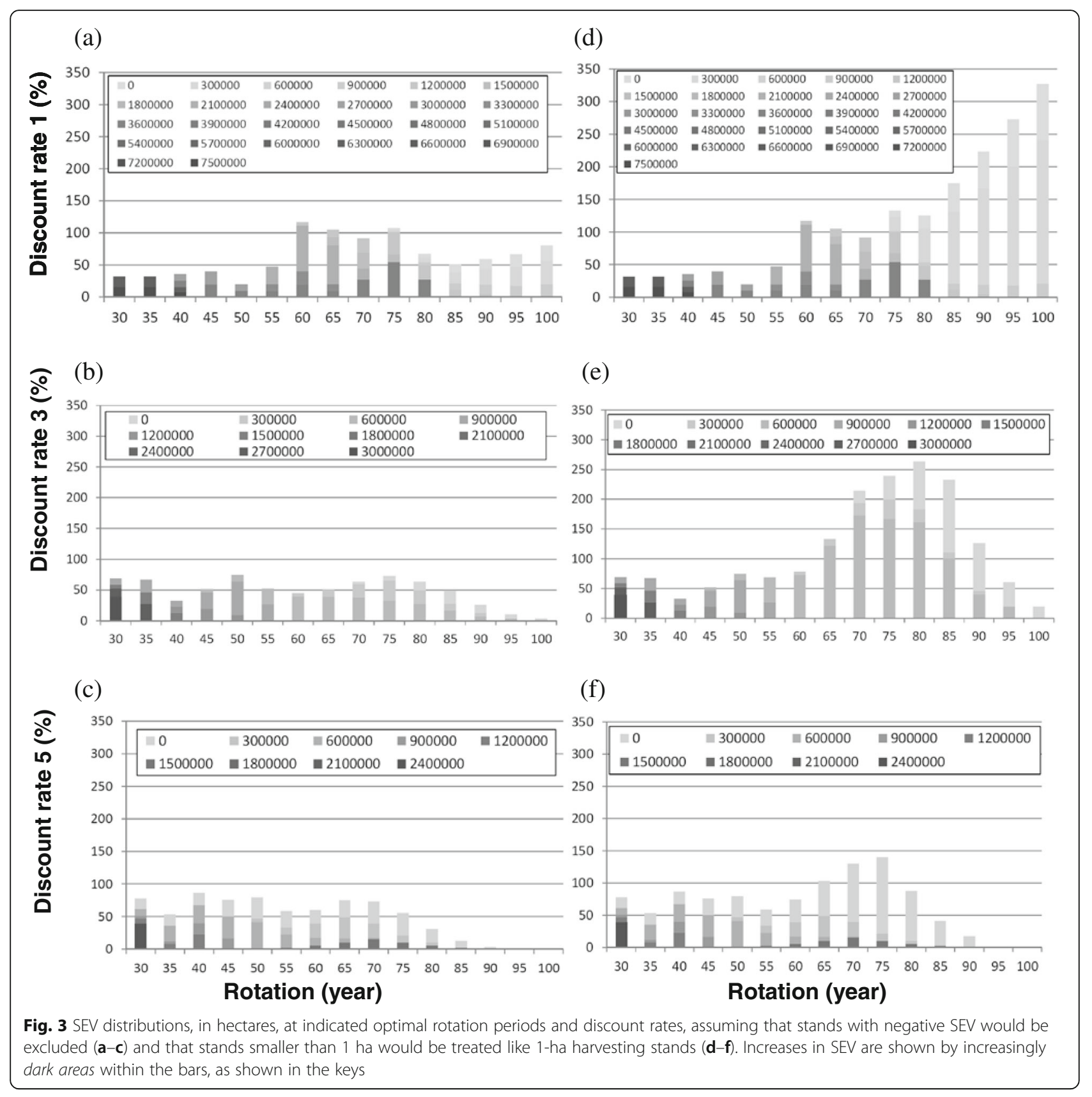

contribution index analysis showed that the key factors affecting forestry profitability, in decreasing order, were discount rate, rotation period, site index, harvesting area and stand age. The discount rate and rotation period determined approximately $90 \%$ of the total profitability. However, a stratification analysis suggested that effects of these two variables could noticeably change with changes to various stand and site factors. Discount rate has been previously shown to significantly affect profitability estimates (Davis et al. 2001; Richard and Puneet 2015), so we expected it to be one of the main factors in our study. Rotation periods determine the harvest intervals for a given stand, so variations in these periods will also affect the profitability of a forest area (Gunalay and Kula 2012). Site index is a measure of the productivity of a stand and thus is likely to reflect harvesting frequency. Increasing the harvesting area can also improve profitability due to the fixed costs of harvesting timber, such as labour and machinery.

When the various small stands are harvested separately, moving the harvesting machines between each site will be associated with certain costs and inefficiency. These costs can be reduced, and the harvesting 
efficiency could improve if these small stands are aggregated into a large harvesting area. The distribution of costs over a large area rather than individual small stands could boost profitability.

Stand age had the smallest effect of the five significant factors, but this variable can influence profitability due to the increase in timber volume as stand age increases. Distances from forest and strip roads did not meet the criteria for inclusion as significant factors, although they influence accessibility of harvesting areas and hence harvesting costs.

An increase in stand area also increased the effects of rotation period, as shown in Fig. 2. The figure illustrates that the optimal rotation period decreases as stand area increases under certain conditions (i.e. Table 1, Additional file 1: Table S1) defined in this study. Although it is relatively difficult to get large amounts of high-quality timber (i.e. the large diameter timber) under shorter rotation periods, the large diameter timber does not have a significant price premium in the target timber market. If we considered the timber market for specific traditional buildings, such as shrines and temples, then the optimal rotation period and silvicultural system would most probably shift.

This is consistent with expectations, as a larger stand area provides greater timber volume per harvesting operation because it can be harvested more efficiently per hectare than a small area, and the rotation period can be reduced while maintaining profitability.

Thus, as shown in the simulations in Fig. 3, small stand areas could be harvested simultaneously to increase profitability in situations where average stand area at the site is smaller than the minimal viable harvesting area (Nakajima et al. 2011b). The relationship between site index and optimal rotation period is also shown in Fig. 2. This result was expected since site index is a key determinant of tree growth rate and usually measured in terms of growth.

The SEV is more sensitive to changes in the discount rate when the discount rate is low $(1-2 \%)$ than when it is high $(2-5 \%)$, as shown in Figs. 1 and 2. Interestingly, the SEV is more sensitive to changes in rotation period when the discount rate is higher. The optimal rotation period increased when the discount rate increased from 3 to 5\% (Fig. 3). Furthermore, Fig. 2 illustrates that optimal rotation period decreases as the harvesting area increases. Thus, the best rotation period for profitability depends on various economic and stand conditions, and a shorter rotation period is not ideal for all situations.

The discount rate is determined by a country's economic conditions. If we regard forestry as a competitive industry, a discount rate of more than $4 \%$ may be appropriate. However, the SEV of certain stands was negative at discount rates under $5 \%$. Hence, there are currently a limited number of profitable stands at the study site, even though it is located in one of the most productive areas for the Japanese forestry industry. In this way, the profitability of an average Japanese forestry area would be even lower than what was estimated in this study. However, as expected, when the discount rate decreased to $3 \%$, and to $1 \%$, the number of stands with a positive SEV increased.

It is not straightforward to solely consider the effects of discount rates for the management of natural resources, as there may be strong ecological, ethical and political pressures to conserve the resources (Heal 2000). However, a discount rate of $1 \%$ is very low for a competitive industry, such as forestry (if the complicating aspects are neglected). In this context, stands that have a negative SEV at a discount rate of $5 \%$ should not be considered as profitable forestry areas. However, large Japanese timber mills require immense amounts of harvested timber for processing to remain profitable. Failure to provide enough raw material to meet these mills' operational demands would severely impair Japanese forestry and associated businesses. Therefore, if the mills are highly profitable, it may be worthwhile, from an economic perspective, to harvest forest stands with slightly negative SEV (via appropriate redistribution of profits) to maintain forestry product supply chains. Another complicating factor is that according to current national forest management plans, more than $30 \%$ of the total clear-cut area in Japan should no longer be maintained as planted forests (Forestry Agency 2014) but regenerated as natural stands, such as mixed hardwood forests. However, such stands should also be predominantly in areas with low profitability (and hence strongly negative SEV and poor fertility).

The densities of the contours in Fig. 2 illustrate the stability of SEV over varying rotation periods and discount rates. A higher density represents lower SEV stability. For example, the SEV is unstable between discount rates of 1 to $2 \%$, as small changes in discount rate strongly affect profitability, but changes in the discount rate above $2 \%$ have weaker effects on SEV. This pattern has been noted in previous studies (Bettinger et al. 2009; Chladná 2007; Davis et al. 2001). The density of contours increases as harvesting area and/or site index increases, as shown in Fig. 2. This suggests that the selection of an optimal rotation period is more important in large areas with high productivity than in small stands (unless numerous small stands can be harvested simultaneously, or they can be harvested simultaneously with large stands).

In addition to these solution spaces, the multiple regression analysis provides further evidence for how the factors included in this study influence SEV. Generally, a larger harvesting area translates into better harvesting efficiency. In this way, it would be reasonable that as harvesting area increases, SEV improves, as was shown in our analyses. Furthermore, previous studies have shown that a higher 
discount rate and/or site index will decrease both the SEV and net present value of a stand (Davis et al. 2001; Nakajima et al. 2011b). The results of our analyses are consistent with previous studies (Bettinger et al. 2009; Davis et al. 2001) and demonstrate that the rotation period length, as well as stand, site and socioeconomic conditions, all have the expected effects on SEV.

Over the last 35 years, the price of timber has decreased, which has reduced forestry profitability and subsequently caused almost all of Japan's forest owners to become dependent on government subsidies. Previous studies have indicated that the intensity of silvicultural practices in an area, including planting, weeding, pruning, pre-commercial thinning and thinning, strongly correlates with the amount of national subsidy available (Hiroshima and Nakajima 2006). Based on previous research and the current forestry situation in Japan, subsidies could be considered as another variable to represent a socioeconomic condition in the calculation of forestry profitability (Nakajima et al. 2011a).

In relation to the categories of factors that affect forestry profitability defined in this study (Table 1), previous studies have considered the stumpage price (Penttinen 2006) and planting density as an economic condition and silvicultural system, respectively. Planting density is also strongly related to future stand conditions. These variables based on the additional data collection could be included in the presented model to determine how they affect forestry profitability. Furthermore, as the simulation system proposed in this study has also been applied to Japanese carbon emission reduction systems (Nakajima et al. 2011c), it could be used to estimate how the carbon price would affect rotation periods. A previous study (Coordes 2014) has shown that this kind of rotation analysis could be applied to adaptive forest management under various uncertainties. Because forest-level adaptive management is related to the aggregation of stand-level simulations within the target forest area, it would be possible to apply these results to adaptive forest management by combining the presented stand-level and forest-level analyses to a selected Japanese forest area.

Various studies have shown how forest profitability is dependent on the discount rate and numerous other variables, such as the carbon tax rate (Chladná 2007). This study employed a solution space to visualise the effects of various factors on forest profitability, measured through SEV. When the results are compared with previous studies (Loisel 2014; Price 2011), our study provides additional information, such as the stability of forest profitability, which is shown by the density of contour lines in the solution spaces (Fig. 2). This stability can provide additional information for forest managers and owners, helping them determine the optimal rotation period.

The multiple regression model used here includes harvesting with a logging vehicle based on relatively high road density. Therefore, the regression analysis should be recalculated if estimates of forest profitability under other harvesting systems, such as skyline harvesting, are desired. However, this result suggested that forest profitability can be expressed through simplified regression models. In this way, the presented regression model has an advantage in that it can estimate forest profitability through simple calculations. Additionally, the Japanese government hopes to increase road construction to encourage harvesting with logging vehicles in the future (Forestry Agency 2014). Therefore, the regression analysis applied in this study, which is based on harvesting with logging vehicles, is logical for estimating forest profitability in Japan.

Certain factors, such as site index, are highly insensitive to the influence of human activity. The application of appropriate fertilisers could increase the productivity of a site, but this practice is not popular in Japanese silviculture, so factors based on natural resources should remain constant. Other site condition factors, such as the harvesting area and rotation period, can be optimised quite easily. The modification of these factors does not raise costs, so it would be easy to increase profitability through, for instance, the synchronisation of harvest times and other silvicultural operations.

Modifications to harvesting area and rotation age are based on the decision-making of forest owners and a harvesting operational schedule, so the modification of these factors does not raise tangible costs, such as additional harvesting equipment expenses or labour costs.

If the total harvesting area in a local forestry area dramatically increases, then supply and demand effects, such as hiring a forestry crew, will increase during periods of high demand. However, even if the total harvesting area remains the same, the synchronisation of harvest times and other silvicultural operations that results from aggregating small stands into a larger area would increase harvesting effectiveness (Hansmann et al. 2016; Kittredge 2005).

Although we did not consider the possibility that the intangible costs (i.e. time spent negotiating the synchronisation of harvest times and other silvicultural operations amongst owners of small stands (Kittredge 2005)) might increase, it would be in the best interest of all forest owners to synchronise harvest times and silvicultural operations by aggregating small stands.

On the other hand, factors such as the establishment of forest roads incur initial physical costs, so changes to these types of factors are not ideal from an economic viewpoint. The most feasible strategy would be to increase the harvesting area with the consensus of forest owners.

The optimal rotation period may have to be recalculated when the harvest times of adjacent stands are synchronised. However, the rotation period should be based 
on the areas with the highest profitability, as changes in the rotation period of these areas can strongly affect overall SEV, and results of the local forest management analysis confirmed the importance of minimising changes to rotation periods in high profitability stands when the rotation period is optimised. The Japanese government has plans to increase forest road density and encourages the simultaneous harvesting of adjacent stands, as well as certain stands that are connected by a forest road (Forestry Agency 2014). Furthermore, according to the forest association interviews, the simultaneous harvesting of adjacent stands, even if they are owned by various private foresters, would be possible in the studied forest area.

An increase in the number of stands harvested per harvesting operation, as suggested, would increase the areas in which the SEV exceeds 0 , and abandoned stands would be subject to active silvicultural management. Abandoned stands usually have high densities, large dead wood contents and poor conditions for sustainable forestry (Nakajima et al. 2011d). Thus, the simultaneous harvesting approach described above could increase the profitable stand area by increasing the area of actively managed stands.

The importance of increasing the total harvesting area by increasing the harvest of stands smaller than 1 ha (following assumption 2) was confirmed through an analysis of how local-scale variations affect rotation period, as illustrated in Fig. 3. Both efficiency and profitability would increase if groups of small adjacent stands were harvested simultaneously. The figure also shows that the rotation period increases when the discount rate rises, due to future returns becoming more attractive.

The national government has suggested that the final cutting area should be expanded to increase national timber production. It is possible that profitable stands could be harvested on a priority basis, as profitable stands typically have shorter rotation optimal periods than less profitable stands. It has also been suggested that the harvested stands should be replanted, with a management objective of maintaining stand and site conditions that most affect forest profitability.

Other studies have analysed uncertainties by including risk variables, such as biomass resources and fire hazards, in the calculations (Shettles et al. 2015; North Carolina Use-Value Advisory Board 2012). Spatial uncertainty in a large forest area has also been addressed (Wei and Murray 2015).

This study provides a starting point for the further analysis of uncertainties related to various factors in forest management. For example, one of the main risks in forest management in Japan is wind. By combining techniques presented in this study and previous research, it would be possible to estimate, and predict, the uncertainty of forestry profitability in Japan associated with wind and other risk factors.

\section{Conclusions}

This study presents a method to estimate and visualise forestry profitability based on variables defined in previous studies. Dimensions of the design space were constructed from previously published forestry inventory data and consisted of two stand condition factors, three site condition factors, one economic condition factor and one silvicultural planning factor. This study used previously published inventory data regarding stand age, site index and tree species. Additionally, the forestry profit simulator was used to estimate the optimal rotation period in terms of soil expectation value. The relationships between SEV and these significant factors were then graphically visualised. The significant factors identified as described above were used to estimate SEV-based profitability distributions, based on the inventory data used to construct the design space and optimal rotation periods, for the studied forest.

The design space included economic and forest stand factors that can affect profitability. A contribution index analysis identified factors that significantly impact profitability, and these factors were then applied to data collected from a forest area in Japan. The effects of the two primary factors, discount rate and rotation period length, on a measure of profitability, the soil expectation value, were visualised in three-dimensional space.

Changes in rotation period affected forestry profitability. However, the effect depended on stand, site and economic conditions. In scenarios characterised by relatively low site productivity index and harvesting area, which results in low profitability, rotation period changes did not have a strong effect on profitability. On the other hand, it was vital to select the optimal rotation period for high profitability areas as even a small deviation had a significant impact on profitability. Furthermore, it was shown that by synchronising the harvesting times of small, adjacent stands, the overall profitability increased through reductions in forest management costs.

These results can help local forest management increase profitability through cooperation with individual forest owners. The presented method also has risk management applications, as it could be used to estimate the effects of external uncertainty variables on forest profitability.

\section{Additional file}

Additional file 1: Table S1. Timber growth functions by site index class (a), planting costs (b), harvesting cost functions (c) and timber prices (d) derived from previous studies (Nakajima et al. 2010; Nakajima et al. 2011a; Nakajima et al. 2011b; Nakajima et al. 2011d; Oka 2006). (DOCX 79.8 kb) 


\section{Acknowledgements}

The authors would like to thank the staff at the Forestry Administration of Miyazaki Prefectural Government for their assistance in the data collection. This study was partly funded by Research Fellowships from the Japanese Science Promotion Society.

\section{Authors' contributions}

NS provided the specialistic information and knowledge regarding the previous and historical research about the rotation periods (L87-103 in revised manuscript). HK provided the logical idea for explaining the fact that the distribution of costs over a large area rather than individual small stands could boost profitability ( $L 402-405$ in revised manuscript) and contributed to the previous harvesting cost model (Nakajima et al. 2011a) used by this study paper. MM was a research project leader regarding the previous forest profitability simulation models (Nakajima et al. 2011a) used by this study paper and provided the specific idea for future vision and relationships between the presented study and previous studies (L477-483 in revised manuscript). All authors read and approved the final manuscript.

\section{Competing interests}

The authors declare that they have no competing interests.

\section{Author details}

'Laboratory of Forest Management, Graduate School of Agricultural and Life Sciences, University of Tokyo, 1-1-1 Yayoi, Bunkyo-ku, Tokyo 113-8657, Japan. ${ }^{2}$ Forestry and Forest Product Research Institute, 1 Matsunosato, Tsukuba 305-8687, Japan. ${ }^{3}$ Hokkaido Research Center, Forestry and Forest Products Research Institute, 7 Hitsujigaoka, Toyohira, Sapporo, Hokkaido 062-8516, Japan

Received: 27 December 2015 Accepted: 11 November 2016 Published online: 26 January 2017

\section{References}

Bettinger, P., Boston, K., Siry, J. P., \& Grebner, D. L. (2009). Forest management and planning. Burlington: Academic.

Boyce, S. G. (1995). Landscape forestry. New York: John Wiley \& Sons.

Cademus, R., Escobedo, F., McLaughlin, D., \& Abd-Elrahman, A. (2014). Analyzing trade-offs, synergies, and drivers among timber production, carbon sequestration, and water yield in Pinus elliotii forests in Southeastern USA. Forests, 5, 1409-1431

Chang, S. J., \& Gadow, K. (2010). Application of the generalized Faustmann model to uneven-aged forest management. Journal of Forest Economics, 16(4), 313-325.

Chladná, Z. (2007). Determination of optimal rotation period under stochastic wood and carbon prices. Forest Policy and Economics, 9(8), 1031-1045.

Coordes, R. (2014). Thinnings as unequal harvest ages in even-aged forest stands. Forest Science, 60(4), 677-690.

Davis, L. S., \& Johanson, K. N. (1987). Forest management. New York: McGraw-Hill.

Davis, L. S., Johanson, K. N., Bettinger, P., \& Howard, T. E. (2001). Forest management to sustain ecological, economic and social values. New York: McGraw-Hill.

Eatwell, J., Milgate, M., \& Newman, P. (1987). The new Palgrave: a dictionary of economics. London: Macmillan.

Faustmann, M. (1968). Calculation of the value which forest land and immature stands possess for forestry, in Gane, ed. 1968a: 27-55, translated by W. Linnard from Allgemeine Forst- und Jagdzeitung, 15 December 1849, 27-55

Forestry Agency. (2007). Annual report on trends of forest and forestry-fiscal year 2006 (p. 17). Tokyo: Japan Forestry Association.

Forestry Agency. (2014). Forestry statistics (p. 260). Tokyo: Japan Forestry Association (in Japanese)

Gu, C. (2002). Smoothing spline ANOVA models. Berlin: Springer-Verlag Inc.

Gulbrandsen, L. H. (2005). Mark of sustainability? Challenges for fishery and forestry ecolabeling. Environment, 47, 8-23.

Gunalay, Y., \& Kula, E. (2012). Optimum cutting age for timber resources with carbon sequestration. Resources Policy, 37, 90-92.

Halbritter, A., \& Deegen, P. (2015). A combined economic analysis of optimal planting density, thinning and rotation for an even-aged forest stand. Forest Policy and Econonics, 51, 38-46.

Hansmann, R., Kilchling, P., \& Seeland, K. (2016). The effects of regional forest owner organizations on forest management in the Swiss Canton of Lucerne. Small-Scale Forestry, 15, 159.
Harrington, C. A. (1990). Alnus rubra Bong. Red Alder. In R. M. Burns \& B. H. Honkala (Eds.), Silvics of North America, volume 2: hardwoods (p. 654). Washington, DC: U. S. Department of Agriculture, Forest Service, Agriculture Handbook.

Hartman, R. (1976). The harvest decision when a standing forest has value. Economic Inquiry, 14(1), 52-58.

Heal, G. (2000). Nature and the marketplace: capturing the value of ecosystem services (p. 203). Washington, DC: Island Press.

Hiley, W. E. (1967). Woodland management (p. 464). London: Faber \& Faber.

Hiroshima, T., \& Nakajima, T. (2006). Estimation of sequestered carbon in Article-3. 4 private planted forests in the first commitment period in Japan. Journal of Forest Research, 11, 427-437.

Hoel, M., \& Sletten, T. M. R. (2016). Climate and forests: the tradeoff between forests as a source for producing bioenergy and as a carbon sink. Resource and Energy Economics, 43, 112-129.

Hornbeck, J. W., \& Swank, W. T. (1992). Watershed ecosystems analysis as a basis for multiple-use management of eastern forests. Ecological Applications, 2, 238-247.

Hyytiäinen, K., Hari, P., Kokkila, T., Mäkelä, A., Tahvonen, O., \& Taipale, J. (2004). Connecting process-based forest growth model to stand-level economic optimization. Canadian Journal of Forest Research, 34, 2060-2073.

IPCC. (2000). Land use, land-use change and forestry. Special report of the intergovernmental panel on climate change (p. 377). Cambridge: Cambridge University Press.

IPCC. (2007). In B. Metz, O. R. Davidson, P. R. Bosch, R. Dave, \& L. A. Meyer (Eds.), Climate change mitigation. Contribution of working group III to the fourth assessment report of the intergovernmental panel on climate change (p. 852). Cambridge: Cambridge University Press.

Kittredge, B. D. (2005). The cooperation of private forest owners on scales larger than one individual property: international examples and potential application in the United States. Forest Policy and Economics, 7, 671-688.

Leona, S. A., Stephen, G. W., \& Raymond, R. R. (1996). Multiple regression: testing and interpreting interactions. Thousand Oaks: Sage Publications.

Loisel, P. (2014). Impact of storm risk on Faustmann rotation. Forest Policy and Economics, 38, 191-198.

Lu, N., Fu, B., Jin, T., \& Chang, R. (2014). Trade-off analyses of multiple ecosystem services by plantations along a precipitation gradient across Loess Plateau landscapes. Landscape Ecology, 29(10), 1697-1708.

Marianov, V., Snyder, S., \& ReVelle, C. (2004). Trading off species protection and timber production in forests managed for multiple objectives. Environment and Planning B: Planning and Design, 31, 847-862.

Millennium Ecosystem Assessment Board. (2005). Millennium ecosystem assessment: ecosystems and human well-being: synthesis (p. 155). Washington, DC: Island Press.

Miyazaki Prefecture Government. (2015). Miyazaki forestry statistical data (p. 179). Miyazaki: Miyazaki Prefecture.

Nakajima, T., Matsumoto, M., Sasakawa, H., Ishibashi, S., \& Tatsuhara, S. (2010). Estimation of growth parameters using the local yield table construction system for planted forests throughout Japan. Journal of Forest Planning, 15(2), 99-108.

Nakajima, T., Kanomata, H., Matsumoto, M., Tatsuhara, S., \& Shiraishi, N. (2011a). Cost-effectiveness analysis of subsidy schemes for industrial timber development and carbon sequestration in Japanese forest plantations. Journal of Forestry Research, 22, 1-12.

Nakajima, T., Kanomata, H., Tatsuhara, S., \& Shiraishi, N. (2011b). Simulation of the spatial distribution of thinning area under different silvicultural subsidy systems in Japanese plantation forests. Folia Forestalia Polonica, 53(1), 3-16.

Nakajima, T., Matsumoto, M., Sakata, K., \& Tatsuhara, S. (2011c). Effects of the Japanese carbon offset system on optimum rotation periods and forestry profits. International Journal of Ecological Economics \& Statistics, 21(11), 1-18.

Nakajima, T., Matsumoto, M., \& Shiraishi, N. (2011d). Modeling diameter growth and self-thinning in planted Sugi (Cryptomeria japonica) stands. The Open Forest Science Journal, 4, 49-56.

North Carolina Use-Value Advisory Board. (2012). Use-value manual. For Agricultural, Horticultural and forest land. NC, USA: North Carolina Use-Value Advisory Board.

Oka, M. (2006). The study of analysis and valuation of harvesting operation by mechanisation (doctoral dissertation). Tokyo: University of Tokyo. (in Japanese. Title translated from Japanese to English)

Olson, D. F., Jr., Roy, D. F., \& Walters, G. A. (1990). Sequoia Semperoirens (D. Don) Endl. Redwood. In R. M. Burns \& B. H. Honkala (Eds.), Sylvics of North America, volume 1: conifers (p. 654). Washington, DC: U.S. Department of Agriculture, Forest Service, Agriculture Handbook. 
Parajuli, R., \& Chang, S. J. (2012). Carbon sequestration and uneven-aged management of loblolly pine stands in the Southern USA: a joint optimization approach. Forest Policy and Econonics, 22, 65-71.

Penttinen, M. (2006). Impact of stochastic price and growth processes on optimal rotation age. European Journal of Forest Research, 125, 335-343.

Pressler, M. R. (1860). For the comprehension of net revenue silviculture and the management objectives derived thereof [in German]. Allgemeine Forst und Jagd-Zeitung, 36, 173-191.

Price, C. (2011). Optimal rotation with declining discount rate. Journal of Forest Economics, 17, 307-318.

Probst, J. R., \& Crow, T. R. (1991). Integrating biological diversity and resource management. Journal of Forestry, 89(1), 12-17.

Pukkala, T. (2002). Multi-objective forest planning (p. 207). Boston: Kluwer.

Richard, B. J., \& Puneet, D. (2015). Optimal forest rotation with multiple product classes. Forest Science, 61, 458-465.

Samuelson, P. (1976). Economics of forestry in evolving society. Economic Inquiry, 14, 466-492.

Shettles, M., Temesgen, H. G., Andrew, N., et al. (2015). Spatial uncertainty in harvest scheduling. Forest Ecology and Management, 354, 18-25.

Social Survey Research Information. (2006). Excel statistics 2006. Tokyo: Social Survey Research Information Co., Ltd.

Wei, R., \& Murray, A. T. (2015). Spatial uncertainty in harvest scheduling. Annals of Operations Research, 232, 275-289.

Westoby, J. (1989). Introduction to world forestry (p. 240). Hoboken: WileyBlackwell.

Winton, J. R. (1951). A dictionary of economic terms: for the use of newspaper readers and students. London: Routledge \& K. Paul.

\section{Submit your manuscript to a SpringerOpen ${ }^{\odot}$ journal and benefit from:}

- Convenient online submission

- Rigorous peer review

- Immediate publication on acceptance

- Open access: articles freely available online

- High visibility within the field

- Retaining the copyright to your article

Submit your next manuscript at $>$ springeropen.com 